\title{
REOPERAÇŌES EM HÉRNIAS INTRA-RAQUEANAS DOS DISCOS INTERVERTEBRAIS LOMBARES
}

\author{
Gilberto Machado de Almeida * \\ Walter C. Pereira*
}

Numerosos trabalhos têm sido publicados a respeito dos resultados obtidos, com a cirurgia, no tratamento das hérnias de discos lombares, mas, de maneira geral, apenas alguns têm referido casos que necessitaram reoperações. Em 1963, Wolinetz e Rosier ${ }^{3}$ apresentaram estudo critico de 15 casos de ciática recidivada após a intervenção. $O$ assunto é interessante e nos levou a rever os casos reoperados nos Serviços de Neurocirurgia do Hospital das Clínicas da Faculdade de Medicina da Universidade de São Paulo (HC) e do Instituto de Aposentadoria e Pensōes dos Ferroviários e Empregados em Serviços Públicos (IAPFESP). Em cêrca de 360 pacientes ( 340 no HC e 20 no IAPFESP) submetidos a laminectomias ou hemilaminectomias por hérnia discal, 22 foram reoperados (20 no $\mathrm{HC}$ e 2 no IAPFESP) por permanência ou recidiva da sintomatologia. Em 4 dos casos ( 2 do $\mathrm{HC}$ e 2 do IAPFESP) a primeira intervenção foi realizada em outros Serviços; nos restantes foi seguida, de maneira geral, a orientação esquematizada por Tenuto ${ }^{2}$.

Consideramos que a primeira intervenção fracassou quando os sintomas permaneceram inalterados ou quando, após certo tempo, surge sintomatologia semelhante à anterior, provocada pela mesma hérnia, não reconhecida no ato cirúrgico ou retirada apenas parcialmente.

As recidivas foram causadas por fibrose pós-operatória, pelo aparecimento de nova hérnia em outro nível ou por herniação do mesmo disco, do lado oposto. A fibrose pós-operatória pode ter tido importância nos casos em que o disco foi curetado incompletamente; preferimos, entretanto, colocar êstes casos no grupo dos fracassos cirúrgicos, desde que a intervenção não foi completa.

Os nossos casos foram assim distribuidos: 1 - fracassos por falha técnica na primeira intervenção, 8 casos (em 2 foi explorado o espaço imediatamente acima ou abaixo do disco herniado, em 5 o disco não foi retirado ou sua curetagem foi incompleta e em um a sintomatologia persistiu pela presença de corpo estranho); 2 - recidivas, 14 casos (4 por fibrose pósoperatória, 9 por hérnia em outro disco e um por herniação no mesmo nível, no lado oposto).

Trabalho da Clinica Neurológica da Faculdade de Medicina da Universidade de São Paulo (Prof. Adherbal Tolosa): * Neurocirurgiões. 
Fracassos por ter sido explorado o espaço errado (2 casos) - Em um caso havia comprometimento das raizes $\mathrm{S}_{1}$, porém, a mielografia mostrou imagem típica de hérnia de disco bilateral em $L_{4}-L_{5}$. Na primeira intervenção não foi encontrada lesão discal, por ter sido feita laminectomia $\mathrm{L}_{-}-\mathrm{L}_{1}$. O quadro clínico permaneceu inalterado e a revisão mielográfica mostrou imagem idêntica à observada no pré-operatório. Nôvo ato cirúrgico permitiu exerese do disco herniado.

No outro doミnte a sintomatologia surgiu após traumatismo raqueano (queda), sendo comprometida a raiz $S_{1}$ à esquerda. A mielografia evidenciou imagem lacunar típica em $\mathrm{L}_{5}-\mathrm{S}_{1}$ à esquerda; entretanto, por engano, foi feita hemilaminectomia $L_{4}-L_{, j}$, sendo encontrada pequena hérnia. Estranhamente a paciente melhorou, passando bem durante 4 anos depois do que, após nova queda, surgiu sintomatologia semelhante à anterior; o exame radiológico mostrou imagem lacunar bilateral em $\mathrm{L}_{i \mathrm{i}}-\mathrm{S}_{1}$, tendo a intervenção cirúrgica confirmado a existência de grande hérnia discal a êste nivel. difícil explicar, neste caso, a melhora obtida após o primeiro ato operatório. Podemos supor, entretanto, que o repouso tenha determinado regressão da sintomatologia que reapareceu após a segunda queda.

Fracassos por ter sido feita operação incompleta (5 casos) - Quatro dêstes pacientes haviam sido operados em outros Serviços, o que não nos permitiu saber exatamente o que foi encontrado no primeiro ato cirúrgico. $O$ que nos foi informado é que, após a intervenção, a sintomatologia permaneceu inalterada ou sofreu melhora transitória. Os exames mielográficos, feitos antes das reoperações, mostraram sempre imagens lacunares grandes e bilaterais em 4 doentes. No único caso em que foi possível comparar as mielografias feitas antes e depois da primeira intervenção cirúrgica verificamos que a imagem lacunar permaneceu pràticamente inalterada.

$\mathrm{Na}$ revisão operatória sempre foi encontrada fibrose; entretanto, o que mais nos chamou a atenção foi o encontro de volumosa hérnia ( 3 casos) ou de restos discais ( 2 casos). Os 3 doentes com disco herniado intacto haviam sido operados em outros Serviços e, portanto, não dispomos de dados precisos a respeito da primeira intervenção. Estes casos comprovam a ineficiência das operações propostas com fins sòmente descompressivos. Nos outros dois enfermos a persistência de fragmentos discais, continuando a estirar a raiz, mostra a necessidade de ser feita curetagem completa do disco.

Fracasso provocado por corpo estranho (1 caso) - A paciente apresentava quadro clínico e mielográfico típico de hérnia entre $L_{5}-S_{1}$ à direita. Foi feita hemilaminectomia no nivel correspondente e curetado o disco comprometido. No pós-operatório a sintomatologia persistiu e mesmo se intensificou, tendo sido indicada nova mielografia, a qual mostrou bloqueio total ao nível de $L_{5}$. Na reoperação, foi verificada a existência de intensa fibrose e de uma bola de algodão ao nível do bloqueio.

Recidivas por fibrose (4 casos) - Nestes doentes houve melhora da sintomatologia por períodos que variaram de 6 meses a 5 anos (média 24 
meses). Em dois casos, a recidiva foi precipitada por esfôrço violento e, em todos, o quadro clínico assemelhava-se ao apresentado anteriormente. Nas revisões mielográficas havia, em todos os casos, grande estreitamento do saco dural no nivel operado, determinando mesmo, em 3 casos, bloqueio parcial ao trânsito do contraste. Nas reoperações, apesar de terem sido realizadas laminectomias relativamente amplas, nada foi encontrado além de intensa e extensa fibrose. Entretanto, existem alguns argumentos que sugerem não ter sido êste elemento o único responsável pela recidiva: a) existiu sempre intervalo relativamente longo entre a intervenção e o reinício da sintomatologia; b) em dois pacientes a recidiva seguiu-se à realização de esfôrço; c) em outros doentes reoperados (casos de recidiva causada por hérnia discal em nível diferente) encontramos fibrose semelhante, sem o quadro clínico correspondente. $\dot{\mathrm{E}}$ possivel, portanto, que outros elementos, provàvelmente relacionados com a estática da coluna, tenham atuado.

Recidivas pela ocorrência de hérnias em outro nivel (9 casos) - A sintomatologia recidivou após período de 6 meses a 12 anos (média 41/2 anos); a não ser em um caso, o reinício do quadro clínico pôde ser correlacionado a traumatismo ou a esfôrço físico mais ou menos violento. $\dot{E}$ interessante referir, como foi salientado por Wolinetz e Rosier 3, que a maioria dêstes doentes exercia funçōes que exigiam esforços físicos violentos ou propiciavam traumatismos repetidos, facilitando a instalação de verdadeira doença discal.

Especificamos abaixo o nível e o lado das hérnias discais encontradas nas duas intervenções, chamando a atenção para o fato de que, na maioria dos casos, elas se localizavam em lados opostos:

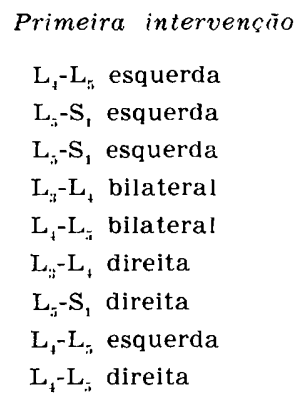

$$
\begin{aligned}
& \text { Segunda intervancióo } \\
& \mathrm{L}_{\mathfrak{j}}-\mathrm{S}_{1} \text { direita } \\
& \mathrm{L}_{4}-\mathrm{L}_{\text {. }} \text { esquerda } \\
& \mathrm{L}_{4}-\mathrm{L}_{j} \text { direita } \\
& \mathrm{L}_{4}-\mathrm{L}_{\bar{\pi}} \text { bilaterai } \\
& L_{3}-L_{1} \text { esquerda } \\
& \mathrm{L}_{7}-\mathrm{L}_{\bar{i}} \text { esquerda } \\
& L_{1}-L_{\text {, }} \text { esquerda } \\
& \mathrm{L}_{\overline{7}}-\mathrm{S}_{1} \text { direita } \\
& \mathrm{L}_{i}-\mathrm{S}_{1} \text { esquerda }
\end{aligned}
$$

No que se refere à mielografia, julgamos indispensável seu emprêgo nos casos de recidiva. Éste exame orientou sempre o diagnóstico correto se bem que, em alguns casos, sua interpretação tivesse sido dificultada, em parte, pela fibrose peridural. A êste respeito é importante salientar que em dois pacientes existia, no nivel em que havia sido realizada a primeira intervençāo, bloqueio parcial ao trânsito do contraste, semelhante ao observado em 3 doentes incluídos no grupo anterior. Entretanto, havia, nos dois casos aqui relatados, sintomatologia irnputável à nova hérnia discal e não à fibrose pós-operatória. 
De maneira geral as reoperaçōes requerem laminectomias amplas, propiciando o exame, não só do nível correspondente à nova hérnia, mas, tambem, do local da primeira intervenção. Foi sempre encontrada fibrose de maior ou menor intensidade, semelhante à observada nos casos de recidiva nos quais apenas êste elemento foi encontrado.

Recidiva de hérnia no mesmo disco, do lado oposto (1 caso) - Êste paciente apresentou, após queda, sintomatologia radicular correspondente à raiz $\mathrm{L}_{\tilde{n}}$, do lado direito. A mielografia mostrou imagem lacunar entre $\mathrm{L}_{4}-\mathrm{L}_{\bar{n}}$ à direita e o ato cirúrgico (hemilaminectomia) confirmou o diagnóstico. $\mathrm{O}$ doente passou bem por 5 anos e, após nova queda, voltou a sentir dor, agora com irradiação correspondente à raiz $\mathrm{L}_{5}$ esquerda. A revisão mielográfica mostrou imagem lacunar entre $\mathrm{L}_{4}-\mathrm{L}_{5}$, do lado esquerdo. No ato cirúrgico (hemilaminectomia $\mathrm{L}_{4}-\mathrm{L}_{5}$ esquerda) foram retirados fragmentos discais expulsos.

Neste caso, uma curetagem mais completa do disco talvez tivesse evitado a recidiva. Não o incluímos, porém, entre os doentes operados incompletamente, pois, após a primeira intervenção, houve melhora acentuada por período de 5 anos e a recidiva ocorreu do outro lado e após nôvo traumatismo.

\section{COMENTÁRIOS}

Muito se tem discutido a respeito da necessidade dos exames radiológicos contrastados em pacientes com lombociatalgia. Alguns autores defendem a mielografia (com contraste lipo ou hidrossolúvel), outros a discografia; alguns prescindem, na maioria dos casos, da radiologia contrastada. Entretanto, quando se trata de estudar nova indicação cirúrgica em doente que já foi operado parece-nos que a mielografia é obrigatória, tanto para julgar da necessidade de reoperar como para orientar o ato operatório. Empregamos de rotina a mielografia com contraste lipossolúvel; outros preferem os hidrossolúveis ${ }^{3}$. A discografia não se justifica nestes casos, pois é impossivel realizá-la no nível operado e, se realizada em outros níveis, não forneceria indicação sôbre a existência de elementos importantes tais como fibrose pós-operatória ou presença de corpos estranhos.

Os resultados das reoperações podem ser considerados bons nos doentes em que pode ser retirada compressão causada por corpo estranho (1 caso) ou por hérnia discal ( 7 vêzes no mesmo local da primeira operação e 10 vêzes em locais diferentes). Conforme foi referido acima, o papel desempenhado pela fibrose peridural na eclosão da sintomatologia parece-nos duvidoso e, nos 4 casos em que ela foi o único elemento encontrado, o resultado da reoperação foi precário.

De maneira geral as reoperações levaram o resultados favoráveis, justificando estudo mais aprofundado dos casos considerados como fracassos cirúrgicos ou recidivas.

A análise dos nossos casos mostra que em 8 pacientes a reoperação poderia ter sido evitada: em dois a exploração foi feita em espaço errado; 
em 3 a operação constou apenas de retirada da lâmina; em 2 o disco não foi curetado completamente e, em um, foi deixado corpo estranho. No caso em que houve aparecimento de nova hérnia, no mesmo disco mas do lado oposto, talvez a recidiva não ocorresse se a curetagem tivesse sido mais completa. Em 9 doentes a reoperação foi devida ao aparecimento de nova hérnia discal em outro nível; êste grupo mostra a necessidade da manutenção de cuidados pós-operatórios (fisioterapia) e de recomendar que os pacientes evitem esforços físicos. Nos 4 casos em que foi encontrada apenas fibrose peridural persistem dúvidas no que diz respeito à explicação da sintomatologia e, portanto, sôbre o que poderia ser feito para evitar a recidiva.

No que se refere à técnica cirúrgica, cumpre salientar novamente a necessidade de curetagem completa do espaço correspondente ao disco herniado, estando contra-indicadas, por ineficientes, as operações chamadas descompressivas.

\section{RESUMO}

Geralmente as reoperações, em doentes com hérnia intra-raqueana dos discos intervertebrais lombares, proporcionam resultados satisfatórios, justificando estudo mais acurado dos casos considerados como fracassos cirúrgicos ou recidivas. Num total de 360 laminectomias e hemilaminectomias por hérnias discais foram encontrados 22 casos que exigiram reoperações. Os casos foram assim distribuídos: 1 - fracassos por falhas técnicas na primeira intervenção, 8 casos (em 2 foi explorado o espaço situado acima ou abaixo do disco herniado, em 5 o disco não foi retirado ou sua curetagem foi incompleta e em um a sintomatologia persistiu devido à presença de corpo estranho); 2 - recidivas, 14 casos (4 por fibrose pós-operatória, 9 por hérnia em outro disco e um por herniação no mesmo nível, do lado oposto.

A análise do material apresentado permite salientar que: há necessidade de curetagem completa do disco lesado; as operações descompressivas não são justificadas; no pós-operatório, ao mesmo tempo em que se impõem cuidados fisioterápicos, os convalescentes devem evitar esforços físicos intensos; a mielografia é o exame ideal quando se estuda a possibilidade de reintervenção.

\section{SUMMARY}

Reoperations on patients with herniated lumbar disc.

As reoperations on patients with lumbar disc herniation are usually successful, a careful study of the cases considered as surgical failures or relapses was made. Among 360 laminectomies and hemilaminectomies for herniated lumbar disc 22 cases needed to be reoperated on. The cases were classified in two groups: 1 - failure caused by technical problems at the first operation, 8 cases (in two of them a wrong disc was explored, in 5 
the disc was not removed or was only partially curetted, in one a cotton pad was left); 2 - relapses, 14 cases ( 4 were caused by fibrosis, 9 by a new prolapse in another disc and one by herniation in the same disc, at the other side).

This study allowed the following conclusions: decompressive operations are not justified; the herniated disc must be completely curetted; after operation the patient must have physiotherapic care and avoid physical strain; myelography is the best test to be done when reoperation is considered.

\section{REFERENCTAS}

1. SICARD, A. - Résultats du traitement chirurgical des sciatiques (d'après 3000 cas opérés). Bull. Acad. Nat. Med. (Paris) 147:469-474, 1963. 2. TENUTO, R. A. - Hérnias intra-raqueanas dos discos intervertebrais lombares: resultados da excisão de 128 casos. Arq. Neuro-Psiquiat. (São Paulo) 17:23-56, 1960. 3. WOLINETZ, E. \& ROSIER, M. - Etude critique de quinze cas de sciatique récidivant après l'intervention. Neuro-chirurgie 9:124-127, 1963.

Clinica Neurológica - Hospital das Clínicas da Faculdade de Medicina da Universidade de São Paulo - Caixa Postal 3461 - Säo Paulo, Brasil. 